\title{
Reports
}

\section{Sprouting as a gardening strategy to obtain superior supplementary food: evidence from a seed-caching marine worm}

\author{
Zhenchang Zhu, ${ }^{1,4}$ Jim van Belzen, ${ }^{1}$ Tao Hong, ${ }^{1}$ Tadao Kunihiro, ${ }^{2}$ Tom Ysebaert, ${ }^{1}$ Peter M. J. Herman, ${ }^{3}$ \\ AND TJEERD J. BOUMA ${ }^{1}$ \\ ${ }^{1}$ Department of Estuarine and Delta Systems, Royal Netherlands Institute for Sea Research (NIOZ) and Utrecht University, \\ Yerseke, 4400AC The Netherlands \\ ${ }^{2}$ TechnoSuruga Laboratory Co., Ltd., Nagasaki 330, Shimizu-ku, Shizuoka, 424-0065 Japan \\ ${ }^{3}$ Marine and Coastal Systems, Deltares, 2629 HD, Delft, The Netherlands
}

\begin{abstract}
Only a handful of non-human animals are known to grow their own food by cultivating high-yield fungal or algal crops as staple food. Here we report an alternative strategy utilized by an omnivorous marine worm, Hediste diversicolor, to supplement its diet: gardening by sprouting seeds. In addition to having many other known feeding modes, we showed using video recordings and manipulative mesocosm experiments that this species can also behave like gardeners by deliberately burying cordgrass seeds in their burrows, which has been previously shown to reduce the loss of seeds to water. These seeds, however, are protected by the seed husk, and we used feeding experiments to show that they were not edible for $H$. diversicolor until they had sprouted or the seed husk had been artificially removed. Additionally, sprouts were shown to be highly nutritious, permitting higher growth rates in $H$. diversicolor than the low-quality basal food, detritus. We propose both a proximate cause (seed husk as a physical barrier) and ultimate cause (nutritional demand) for this peculiar feeding behavior. Our findings suggest that sprouting may be a common strategy used by seed-collecting animals to exploit nutrients from well-protected seeds.
\end{abstract}

Key words: cordgrass; gardening; ragworm; seed; seed-caching; Spartina; sprout; sprouting.

\section{INTRODUCTION}

Agriculture, defined as the cultivation of high-yield staple foods, was a pivotal development in human history, yet it is not a human monopoly. Long before the arrival of human agriculture, at least three terrestrial invertebrate lineages had independently evolved the ability to grow fungi, including ants, termites and ambrosia beetles (Farrell et al. 2001, Aanen et al. 2002, Mueller et al. 2005). More recently, marine animals have also been documented to cultivate foods, including fungal-farming snails (Silliman and Newell 2003) and damselfish that grow algae (Hata and Kato 2006). Despite different cultivation strategies, all these animal farmers are able to achieve a sufficient supply of their staple food to sustain themselves from their high-yield fungal or algal crops.

Here we identify a novel, sprout-based, gardening strategy utilized by the common ragworm species Hediste

Manuscript received 13 June 2016; revised 16 September 2016; accepted 27 September 2016. Corresponding Editor: Steven C. Pennings.

${ }^{4}$ E-mail: zhenchang.zhu@nioz.nl diversicolor (Fig. 1a). This species is widely distributed along intertidal flats that often neighbor salt marsh pioneer plants like cordgrass in the NW Atlantic (Olivier et al. 1996, Paramor and Hughes 2007). Although $H$. diversicolor is an opportunistic omnivore that does not rely on a single food source, we present evidence that this species can also behave like a gardener, growing nutritious supplementary rather than high-yield staple food. They have been shown to deliberately bury cordgrass seeds into their burrows, thereby reducing seed loss to hydrodynamic processes (Marion and Orth 2012, Zhu et al. 2014). While ragworms were thought to be seed predators (Emmerson 2000, Paramor and Hughes 2004), the direct consumption of intact cordgrass seeds had never been observed. In fact, only dehusked cordgrass seeds were found to be consumed (Emmerson 2000), suggesting that the husks protect seeds from consumption. In this paper, we present evidence that $H$. diversicolor can actually acquire nutrients from these well-protected seeds by sprouting them.

With highly concentrated nutrients stored to sustain subsequent plant growth and development, seeds are 


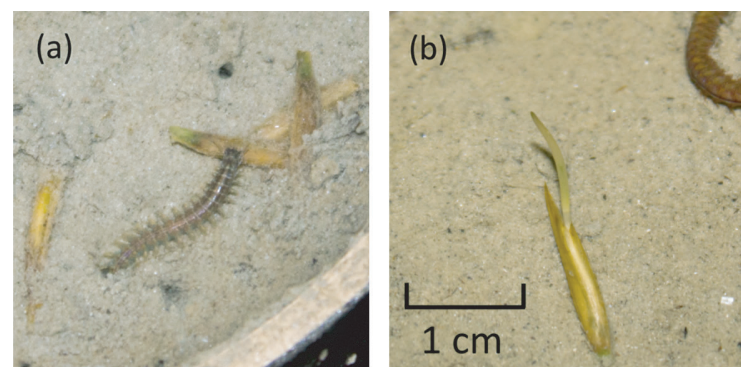

(c)

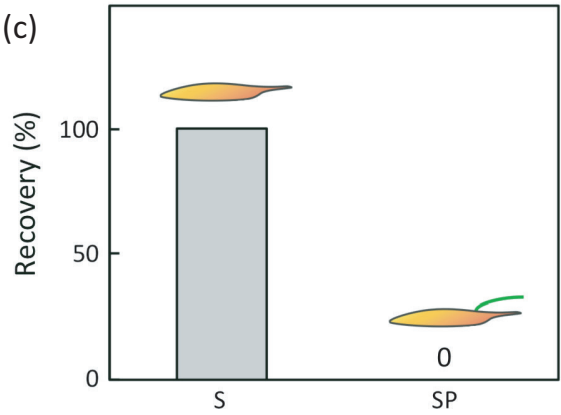

FIG. 1. (a) Hediste diversicolor collecting a cordgrass seed (ca. $1.8 \mathrm{~cm}$ length, $0.2 \mathrm{~cm}$ width). (b) Sprouting cordgrass seed. (c) The recovery percentage of sterile seeds (S) and sprouting seeds (SP) at the end of the $H$. diversicolor feeding experiment (3 weeks). All sprouts had been excised, whereas all the sterile seeds were recovered intact.

often an attractive food resource for animals across ecosystems (Hulme and Benkman 2002). Nevertheless, seeds may not always be directly consumed due to their big size, physical defenses (e.g., hard seed coat) and/or chemical protection (e.g., toxins) (Hulme and Benkman 2002, Vander Wall 2010). By a process of natural conversion, sprouting can improve digestibility and nutritional quality, compared with non-sprouted seeds (Chavan and Kadam 1989). Sprouting for food (e.g., soy sprouts) has previously only been observed in human behavior. Sprouted foods, which have been part of East Asian diets for centuries, are currently becoming popular in the western world because of their high nutritional value, including high protein, amino acid and vitamin content (Chavan and Kadam 1989).

High-protein diets (e.g., alga) have been shown to enhance growth rates and reproductive success of H. diversicolor (Olivier et al. 1996, Nesto et al. 2012). However, the most abundant food source in tidal flats, i.e., sedimentary organic matter such as detritus, is of low quality due to low nitrogen content (Dauwe et al. 1999, Herman et al. 1999). This poor quality of the basal resource fosters omnivory as a general strategy in benthic communities (Herman et al. 1999, HilleRisLambers et al. 2006), as omnivory allows for feeding on both abundant, low quality food and less abundant, more nutritious food (Coll and Guershon 2002). To meet its nutritional requirements, $H$. diversicolor displays many adaptations to obtain a more nitrogen-rich diet, such as grazing of diatoms (e.g., Smith et al. 1996) and algae (e.g., Olivier et al. 1996), and predation of macrozoobenthos (e.g., Rönn et al. 1988). In this study, we examine the hypothesis that seed-caching behavior and sprout consumption can enable the omnivorous $H$. diversicolor to supplement its diet with high quality food, using manipulative mesocosm experiments.

\section{Methods}

\section{Living and feeding habits of $\mathrm{H}$. diversicolor}

The common ragworm, $H$. diversicolor, is an opportunistic omnivore living in semi-permanent $\mathrm{U}$ - or Y-shaped burrows, with a life span of 1-3 yr. The individual burrow is a well-defined territory and may develop into multi-branched structures over time. This species has a wide array of different feeding strategies: filter feeding, deposit feeding, scavenging, and predation. For the last three strategies, the worm partially emerges from the burrow, feeding on the sediment around the burrow or taking a proboscis full of material (e.g., plant/animal remains) from the surface and retreating into the burrow. It can hunt for small invertebrates, seizing them with its strong jaws (reviewed in Scaps 2002). This species has also been suggested to stimulate bacterial growth (i.e., microbial gardening) in its burrow, where constant irrigation maintains aerobic conditions favorable for bacterial growth, as found in other marine worms, e.g., Abarenicola vagabunda (Hylleberg 1975, Scaps 2002). H. diversicolor can grasp soft plant materials like seagrass leaves, break them and pull them into its burrow (Hughes et al. 2000). More recently, H. diversicolor (Delefosse and Kristensen 2012) and its close relatives, Alitta virens (Zhu et al. 2016) and Neanthes succinea (Blackburn and Orth 2013), have been reported to collect and bury seeds of seagrass (Delefosse and Kristensen 2012), glasswort (Paramor and Hughes 2004) and cordgrass (Emmerson 2000, Zhu et al. 2016). However, direct seed consumption has only been reported for the seagrass Zostera noltii (Hughes et al. 2000), which has small seeds of about $2 \mathrm{~mm}$ in length.

\section{Food preference for seeds vs. sprouts}

To test the hypothesis that cordgrass seeds (c.a. $1.8 \mathrm{~cm}$ length, Fig. 1a) cannot be consumed by $H$. diversicolor unless they have sprouted, we conducted a mesocosm experiment in a climate room $\left(18^{\circ} \mathrm{C}\right)$, using both sterile seeds and sprouting seeds as food sources. This experiment lasted for 3 weeks, during which the foraging behavior of ragworms and the state of the food items was monitored daily by direct visual observation. In the end, recovery (percentage) of dead and sprouted seeds was determined to quantify which types of seeds were eaten more often. Because $H$. diversicolor is sensitive to human presence, we additionally set up a microcosm equipped with a webcam system (Logitech ${ }^{\circledR}$ HD Webcam c615) to observe the feeding behavior of this animal. 


\section{Seed redistribution and viability after handling by H. diversicolor}

To examine the effects on seed redistribution and seed viability from handling and burial by $H$. diversicolor, we conducted a mesocosm experiment using PVC cylinders filled with defaunated muddy sediment, involving two worm-treatments, (1) "worm + surface seeds" (WS) and (2) "worm + buried seeds" (WB), and two control treatments, (1) surface seeds (CS) and (2) buried seeds (CB). For WB and CB, seeds were buried at $1 \mathrm{~cm}$ depth, the typical depth at which ragworms bury seeds (Delefosse and Kristensen 2012, Blackburn and Orth 2013, Zhu et al. 2016). To avoid germination during incubation, we conducted the experiment in the winter (January 2014) in a green house where the temperature fluctuated between $3-12^{\circ} \mathrm{C}$, using cordgrass seeds without any stratification treatments that had been harvested 2 months beforehand (November 2013). Incubation lasted for 4 weeks, during which active seed transport by $H$. diversicolor was frequently observed. Seed germination was not seen in the any of the treatment groups. After incubation, seed distribution was determined by slicing each sediment core, and viability of all the retrieved seeds was determined via a germination test. Total germination (percentage) was calculated for each treatment and control group.

\section{Consequences of nutrition on $\mathrm{H}$. diversicolor growth}

To examine the benefits of sprout consumption, we tested the hypothesis that sprouted seeds enable $H$. diversicolor to exploit the rich nutrients stored in cordgrass seeds, thus further improving the nutritional quality of their diet. We first performed a feeding experiment in a climate room $\left(18^{\circ} \mathrm{C}\right)$ to compare the growth of $H$. diversicolor under four different diet types: (1) muddy sediment + intact sterile seeds $(\mathrm{M}+\mathrm{S})$; (2) muddy sediment + dehusked sterile seeds (M+DS); (3) muddy sediment + sprouted seeds $(\mathrm{M}+\mathrm{SP})$; and (4) muddy sediment only (M). This experiment was conducted in plastic cups filled by muddy sediment with one individual worm in each cup. Except for diet type M, each individual was fed every $3 \mathrm{~d}$ with one intact, dehusked or sprouted seed for a total of eight times. After 4 weeks, the growth of each individual was determined by calculating the change in fresh weight (\%), expressed as the following: 100\%* (Final weight - Initial weight)/Initial weight. Some of the worms were found to be dead or missing from the cups. The missing worms were recovered from the bottom of the container used to hold the cups but were excluded from the data analysis, as it was not possible to determine when and from which cups these worms had escaped. To compare the nutritional value of each diet, organic carbon content (OC) and total nitrogen content (TN) were quantified for sprouts, dehusked seeds, seed husks and the muddy sediment. The carbon to nitrogen ratio $(\mathrm{C}: \mathrm{N})$ was then calculated as $\mathrm{OC} / \mathrm{TN}$.
For further details regarding all the above-mentioned experiments, observations and measurements, refer to the supplementary information (Appendix S1).

\section{Statistics}

Prior to analysis, we conducted Shapiro-Wilk tests to check for data normality. One-way ANOVA was used to detect the effects of $H$. diversicolor handling and burial on seed viability. We conducted ANCOVAs to compare the weight change of $H$. diversicolor between diet treatments, using initial weight as the covariate. To satisfy the assumption of normality, the data were $\log (\mathrm{x}+0.5)$ transformed. We performed a Pearson's chi-square test to examine if worm mortality differed between the diet treatments. All statistical analyses were conducted in R (http://www.R-project.org), applying a significance level of $\alpha=0.05$.

\section{Results}

Our experiment revealed that $H$. diversicolor had a marked preference for sprouted seeds. All sprouts were found to be missing after 3 weeks, whereas all the sterile seeds were recovered intact, indicating lack of germination or predation (Fig. 1c). During the experiment, we observed $H$. diversicolor attempting to collect both the sterile and sprouted seeds around their burrows, and pulling some of them inside. The video recordings revealed $H$. diversicolor cutting the sprout off a germinated seed and eventually pulling it into its burrow (Appendix S2: Video S1).

Seed viability was not affected by the handling and burial of the seeds by $H$. diversicolor (Fig. 2). For the "worm + surface seeds" (WS) treatment, all the seeds were redistributed by $H$. diversicolor and ca. $25 \%$ of the seeds were recovered from their burrows, mostly within the top $1 \mathrm{~cm}$ (Fig. 2b). For the treatment of "worm + buried seeds", only $1 \%$ of the seeds were found deeper $(1-2 \mathrm{~cm})$ than the original depth $(0-1 \mathrm{~cm})$, suggesting very limited vertical redistribution by $H$. diversicolor. Neither the handling nor the shallow seed burial affected seed viability (Fig. 2c), as the subsequent germination test showed that there was no significant difference (One-way ANOVA, $P=0.89$ ) between the treatment and control groups.

The diet types were important in determining the growth of $H$. diversicolor (Fig. 2d). The differences in growth rate could be explained by the variation in nutritional values (Table 1). Sprouts and dehusked seeds are both protein-rich, while the basal food source (i.e., particulate organic matter in the mud) and seed husks have much lower nitrogen content. The diet with sprouted seeds led to a significantly higher weight increase (ANCOVA, $P<0.05$ ) than that with muddy sediment or sterile intact seeds. The dehusked seed itself also proved to be nutritious, contributing to a significantly higher weight increase than the intact seeds (ANCOVA, 


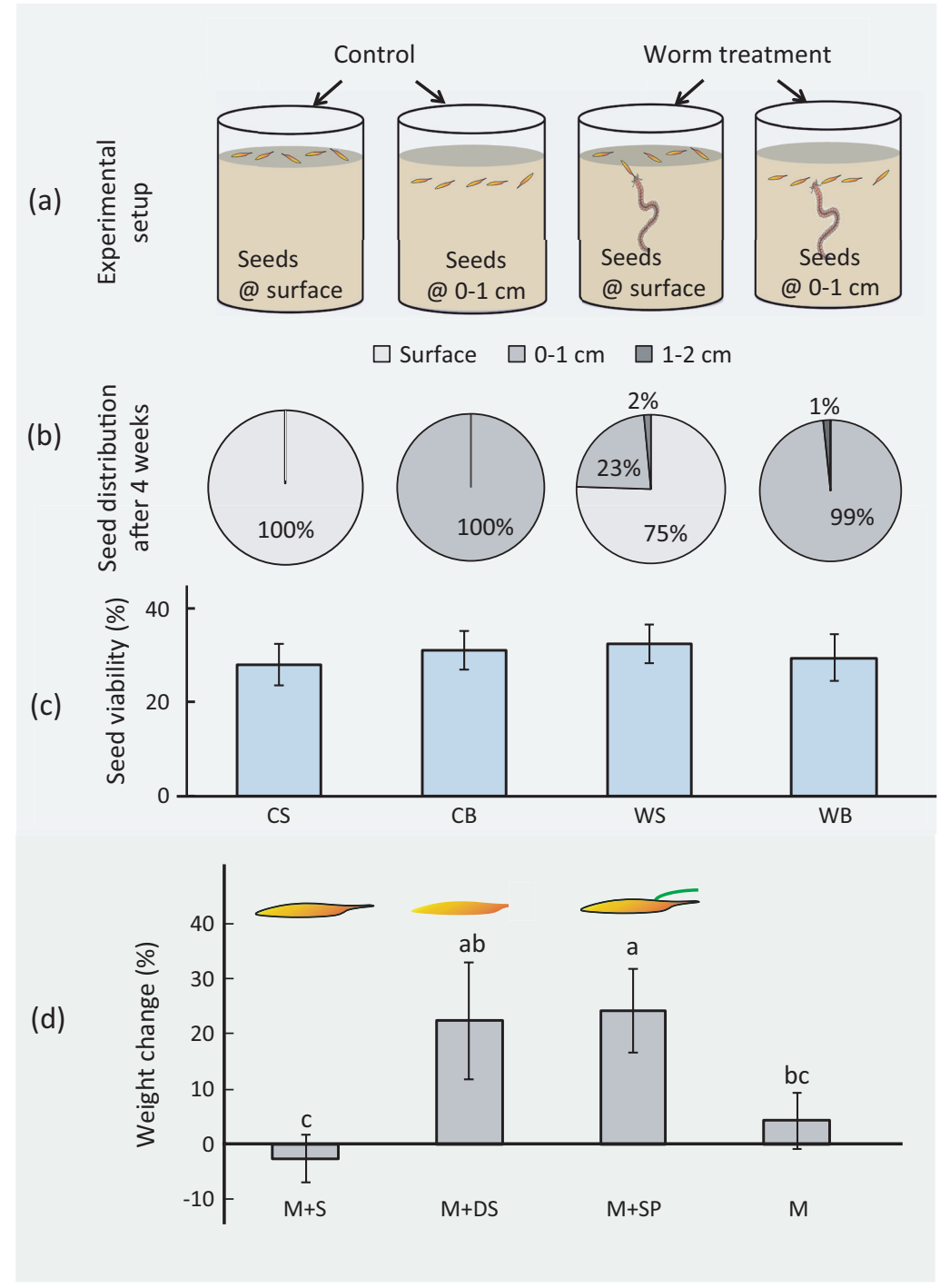

FIG. 2. (a) Setup of experiment on seed redistribution and viability after handling by Hediste diversicolor (b) Vertical distribution of the seeds retrieved from the two experimental treatments "worm + surface seeds" (WS) and "worm + buried seeds" (WB), and two control treatments with surface seeds (CS) or buried seeds (CB). (c) No significant difference were found in total germination (mean $\pm \mathrm{SE}, n=200$ ) of retrieved seeds between treatment groups (ANOVA, $P=0.89$ ). (d) Weight change (mean $\pm \mathrm{SE}$ ) in $H$. diversicolor fed with four different diets: (1) muddy sediment + intact seeds $(\mathrm{M}+\mathrm{S}), n=15 ;(2)$ muddy sediment + dehusked seeds $(\mathrm{M}+\mathrm{DS}), n=12$; (3) muddy sediment + sprouting seeds $(\mathrm{M}+\mathrm{SP}), n=12$; and (4) muddy sediment only $(\mathrm{M}), n=12$. Lower case letters identify significantly different means (ANCOVA, $P<0.05$ ).

$P<0.05)$, suggesting that the seed husk serves as a physical barrier against direct seed consumption.

There were no detectable differences in growth between individuals eating sprouted and dehusked seeds, although the mean dry weight of a sprout $(1.2 \mathrm{mg})$ is only $21.8 \%$ that of a dehusked seed $(5.5 \mathrm{mg})$. Sprouts have a comparable C:N ratio with the macroalgae species Enteromorpha intestinalis (Table 1), which has previously been shown to yield rapid growth of $H$. diversicolor (Olivier et al. 1996). The dehusked seeds have a higher $\mathrm{C}: \mathrm{N}$ ratio than sprouts (Table 1), suggesting that sprouting improves both food accessibility and quality for $H$. diversicolor. No difference in worm mortality between treatments could be detected (chi-square test, $P=0.79$ ), suggesting that the few dead worms in the experiment did not result from the diet. When all the living worms had been recovered, all the sterile seeds were eventually retrieved intact without the occurrence of germination or predation, while only $8.3 \%$ of the dehusked seeds were recovered. All sprouts had been excised from the sprouted seeds and were missing.

\section{DisCUSSION}

Animal seed dispersers like rodents and earthworms often directly consume seeds as the reward (Brown and Ojeda 1987, Hulme and Benkman 2002); however, we 
TABLE 1. Nutritional quality of dehusked cordgrass seeds cordgrass sprouts, seed husks, and the muddy sediment used in our experiments. Measurements of organic carbon (OC) and total nitrogen (TN) content for each item were based on bulk samples with one replicate each and conducted in analyzer FlashEA 1112. Except for the muddy sediment, the measurements were later repeated using separate bulk samples analyzed with a different instrument: vario MICRO cube. The nutritional quanlity data from the literature for one macroalgae species Enteromorpha intestinalis, and two marine vascular plants Spartina anglica (i.e., cordgras) and Halimione portulacoides, were also included for comparsions.

\begin{tabular}{lccc}
\hline \hline Food item & $\begin{array}{c}\text { OC }(\% / \text { dry } \\
\text { weight })\end{array}$ & $\begin{array}{c}\text { TN }(\% / \text { dry } \\
\text { weight) }\end{array}$ & C:N ratio \\
\hline Dehusked seeds & $30.5^{*}$ & $2.8^{*}$ & 10.9 \\
& $30.8 \dagger$ & $2.8 \dagger$ & 11.0 \\
Sprouts & $28.8^{*}$ & $3.6^{*}$ & 7.9 \\
& $28.2 \dagger$ & $3.7 \dagger$ & 7.6 \\
Seed husks & $45.5^{*}$ & $0.7^{*}$ & 61.0 \\
& $44.4 \dagger$ & $0.8 \dagger$ & 55.5 \\
Mud & $1.0^{*}$ & $0.2^{*}$ & 5.3 \\
Enteromorpha intestinalis & $45.4 \ddagger$ & $5.17 \ddagger$ & 8.8 \\
Spartina anglica & $48.0 \ddagger$ & $1.4 \ddagger$ & 34.4 \\
Halimione portulacoides & $1.0 \ddagger$ & $0.2 \ddagger$ & 21.2 \\
\hline
\end{tabular}

*Analyzed with FlashEA 1112

Analyzed with vario MICRO cube.

Source: Olivier et al. 1996.

illustrate that the common ragworm $H$. diversicolor can benefit from seed burial by sprouting the buried seeds to produce high-quality food. Sprouting enables $H$. diversicolor, which feeds primarily on poor-quality food (Scaps 2002), to exploit the rich nutrients in cordgrass seeds protected by their husks. We reveal that initial failure in directly consuming intact seeds can result in improved food accessibility, higher nutritional values and associated higher weight increase. After burial, no further action is needed by these worms to tend their gardens besides not moving too far away during the period between seed burial and germination.

The dispersal of cordgrass seeds starts in autumn (October), and extends to the winter and early spring (March) of the following year, with very few seeds germinating during this dispersal period (Huiskes et al. 1995). Cordgrass seedlings mainly emerge in spring (April) and germination may extend to summer as some seeds can remain viable in the seed bank until July, but no seeds were found to survive by the end of the growing season (Groenendijk 1986). Therefore, the waiting time for seedcaching $H$. diversicolor to harvest their sprouts may vary from a few weeks to a few months. Given that this worm lives in a semi-permanent burrow and has a life span of 1-3 yr (Scaps 2002), seed caching by this species can reasonably be assumed to result in sprout consumption, provided that the worms are not predated and the seeds remain viable during the waiting period.

As not every seed eventually germinates (Fig. 2c), seed burial by $H$. diversicolor might not always result in sprout consumption. Given its relatively short seed longevity
( $<1 \mathrm{yr}$, Wolters and Bakker 2002), however, it is likely that the buried cordgrass seeds that fail to germinate will decompose in the burrow, and the detritus may eventually be consumed by $H$. diversicolor. The decomposed seeds could still be nutritious because of the high energy storage and richer nitrogen than other plant debris (Table 1), but they would still be inferior to the freshly sprouted food as the latter has a lower $\mathrm{C}: \mathrm{N}$ ratio (this study), is more easily digested and is richer in micronutrients, e.g., vitamins (Chavan and Kadam 1989). Although ragworms have been previously suggested to stimulate microbial growth in their burrows (Hylleberg 1975, Scaps 2002), our experiments showed that ragworm handling did not actually facilitate seed decay, as neither decomposition of intact seeds nor effects on seed viability were observed. Moreover, microbial activity can be expected to be low during the period between seed dispersal and germination, i.e., winter and early spring, because of the low temperatures.

Seed consumption and seedling herbivory by $H$. diversicolor could, in some cases, form a major bottleneck for vegetation (re-)establishment from seed in low-lying tidal areas (Emmerson 2000, Hughes et al. 2000, Paramor and Hughes 2004). Paradoxically, the inability to directly consume seeds may, however, improve the chances for cordgrass establishment if some ragworms die or are predated before seed germination. Consequently, burial does not necessarily end up with all sprouts being consumed and may incidentally result in directed dispersal, which can increase seed persistence by decreasing seed removal caused by the tide (Zhu et al. 2014).

Sprouting may also be found for other ragworm species (e.g., Alitta virens and Neanthes Succinea), given their comparable feeding behaviors and niches (Blackburn and Orth 2013, Zhu et al. 2016). Similarly, this phenomenon also likely occurs for seeds of other macrophytes, e.g., seagrass and glasswort, that can be cached by ragworms (Paramor and Hughes 2004, Delefosse and Kristensen 2012), provided that their seed coats can prevent immediate seed consumption. Moreover, sprouting may be more widespread as a feeding strategy, given that analogous seed-caching behavior has been seen in earthworms (Regnier et al. 2008, Forey et al. 2011). These terrestrial worms primarily feed on lowquality detritus (Curry and Schmidt 2007) and are able to obtain nutrients from high-quality food sources like seeds and germinated seeds (Shumway and Koide 1994, Eisenhauer et al. 2009, 2010). Thus, sprout-based gardening involving active seed burial may also have developed in seed-earthworm systems, when seeds are not directly edible due to large sizes or hard seed coats. This could be especially relevant in cases when seed germination is enhanced by earthworm gut passage, as found for some plant species (Eisenhauer et al. 2009).

Sprouting as a solution to utilize the nutrients from well-secured seeds may also apply to other seed-caching animals. Possible candidates are rodents that cache nuts and seeds with hard shells or with tannins that reduce the 
immediate food value (Hulme and Benkman 2002, Vander Wall 2010), as such animals also consume young seedlings (e.g., Ostfeld and Canham 1993, Ostfeld et al. 1997). For instance, a study on meadow voles revealed that consumption of fresh green foods like sprouted wheat allowed for rapid growth and development in young meadow voles (Meek et al. 1995). In addition, a previous study on the leaf-cutting ant Atta sexdens also suggested that seed-caching ants might also use sprouted seeds as a food source. These ants were found to cut the epicotyl from the sprouting seeds of non-myrmecochorous plants (Silva et al. 2007).

Besides humans, very few animal species have been reported to "grow" their own food. While most of these farming species have been characterized by cultivation of high-yield fungal or algal crops as their staple food, sprouting by omnivorous seed-caching ragworms, as presented here, serves as a novel type of gardening strategy that yields superior supplementary food. Unlike human agriculture, gardening or farming by invertebrates seems more likely to be an adaptive feeding strategy to obtain nourishment, without such animals being conscious of or intentional in their behavior (e.g., Farrell et al. 2001, Silliman and Newell 2003, Mueller et al. 2005). Seed caching by $H$. diversicolor, however, still yields highquality sprouted food, analogous to the sprouting practices found in humans (e.g., soy sprouts). We propose both a proximate cause (protection by seed husk) and ultimate cause (nutritional demand) for this feeding behavior. Given the ubiquity of seed-protecting mechanisms (Hulme and Benkman 2002, Vander Wall 2010), sprouting may be a common strategy used by many seedcollecting animals to exploit nutrients from otherwise well-protected seeds.

\section{ACKNOWLedgments}

We thank Lennart van IJzerloo, Jeroen van Dalen and Aniek van de Berg for their assistances in experimental preparation. We thank Steven Pennings and two anonymous reviewers for providing very useful comments to improve this manuscript, and Esther Chang for language editing. We gratefully acknowledge the financial support from the BE-SAFE Project financed primarily by NWO, the EU-funded THESEUS Project and the China Scholarship Council.

\section{Literature Cited}

Aanen, D. K., P. Eggleton, C. Rouland-Lefevre, T. GuldbergFroslev, S. Rosendahl, and J. J. Boomsma. 2002. The evolution of fungus-growing termites and their mutualistic fungal symbionts. Proceedings of the National Academy of Sciences of the United States of America 99:14887-14892.

Blackburn, N. J., and R. J. Orth. 2013. Seed burial in eelgrass Zostera marina: the role of infauna. Marine Ecology Progress Series 474:135-145.

Brown, J. H., and R. A. Ojeda. 1987. Granivory: patterns, processes, and consequences of seed consumption on two continents. Revista Chilena de Historia Natural 60:337-349.

Chavan, J. K., and S. S. Kadam. 1989. Nutritional improvement of cereals by sprouting. Critical Reviews in Food Science and Nutrition 28:401-437.
Coll, M., and M. Guershon. 2002. Omnivory in terrestrial arthropods: mixing plant and prey diets. Annual Review of Entomology 47:267-297.

Curry, J. P., and O. Schmidt. 2007. The feeding ecology of earthworms - A review. Pedobiologia 50:463-477.

Dauwe, B., J. J. Middelburg, P. Van Rijswijk, J. Sinke, P. M. J. Herman, and C. H. R. Heip. 1999. Enzymatically hydrolyzable amino acids in North Sea sediments and their possible implication for sediment nutritional values. Journal of Marine Research 57:109-134.

Delefosse, M., and E. Kristensen. 2012. Burial of Zostera marina seeds in sediment inhabited by three polychaetes: laboratory and field studies. Journal of Sea Research 71:41-49.

Eisenhauer, N., M. Schuy, O. Butenschoen, and S. Scheu. 2009. Direct and indirect effects of endogeic earthworms on plant seeds. Pedobiologia 52:151-162.

Eisenhauer, N., O. Butenschoen, S. Radsick, and S. Scheu. 2010. Earthworms as seedling predators: importance of seeds and seedlings for earthworm nutrition. Soil Biology and Biochemistry 42:1245-1252.

Emmerson, M. 2000. Remedial habitat creation: Does Nereis diversicolor play a confounding role in the colonisation and establishment of the pioneering saltmarsh plant, Spartina anglica? Helgoland Marine Research 54:110-116.

Farrell, B. D., A. S. Sequeira, B. C. O'Meara, B. B. Normark, J. H. Chung, and B. H. Jordal. 2001. The evolution of agriculture in beetles (Curculionidae: Scolytinae and Platypodinae). Evolution 55:2011-2027.

Forey, E., S. Barot, T. Decaens, E. Langlois, K.-R. Laossi, P. Margerie, S. Scheud, and N. Eisenhauere. 2011. Importance of earthworm-seed interactions for the composition and structure of plant communities: a review. Acta OecologicaInternational Journal of Ecology 37:594-603.

Groenendijk, A. M. 1986. Establishment of a Spartina-anglica population on a tidal mudflat - A field experiment. Journal of Environmental Management 22:1-12.

Hata, H., and M. Kato. 2006. A novel obligate cultivation mutualism between damselfish and Polysiphonia algae. Biology Letters 2:593-596.

Herman, P., J. Middelburg, J. Van de Koppel, and C. Heip. 1999. Ecology of estuarine macrobenthos. Advances in Ecological Research 29:195-240.

HilleRisLambers, R., J. Van de Koppel, and P. M. J. Herman. 2006. Persistence despite omnivory: benthic communities and the discrepancy between theory and observation. Oikos 113:23-32.

Hughes, R. G., D. Lloyd, L. Ball, and D. Emson. 2000. The effects of the polychaete Nereis diversicolor on the distribution and transplanting success of Zostera noltii. Helgoland Marine Research 54:129-136.

Huiskes, A. H. L., B. P. Koutstaal, P. M. J. Herman, W. G. Beeftink, M. M. Markusse, and W. D. Munck. 1995. Seed dispersal of halophytes in tidal salt marshes. Journal of Ecology 83:559-567.

Hulme, P. E., and C. W. Benkman. 2002. Granivory. Pages 132 154 in C.M. Herrera, and O. Pellmyr, editors, Plant-animal interactions. An evolutionary approach Blackwell Oxford, UK.

Hylleberg, J. 1975. Selective feeding by Abarenicola pacifica with notes on Abarenicola vagabunda and a concept of gardening in lugworms. Ophelia 14:113-137.

Marion, S. R., and R. J. Orth. 2012. Seedling establishment in eelgrass: seed burial effects on winter losses of developing seedlings. Marine Ecology Progress Series 448:197-207.

Meek, L. R., T. M. Lee, and J. F. Gallon. 1995. Interaction of maternal photoperiod history and food type on growth and reproductive development of laboratory meadow voles 
(Microtus pennsylvanicus). Physiology and Behavior 57 905-911.

Mueller, U. G., N. M. Gerardo, D. K. Aanen, D. L. Six, and T. R. Schultz. 2005. The evolution of agriculture in insects. Annual Review of Ecology Evolution and Systematics 36:563-595.

Nesto, N., R. Simonini, D. Prevedelli, and L. Da Ros. 2012. Effects of diet and density on growth, survival and gametogenesis of Hediste diversicolor (OF Muller, 1776) (Nereididae, Polychaeta). Aquaculture 362:1-9.

Olivier, M., G. Desrosiers, A. Caron, C. Retiere, and A. Caillou. 1996. Juvenile growth of Nereis diversicolor (O.F. Muller) feeding on a range of marine vascular and macroalgal plant sources under experimental conditions. Journal of Experimental Marine Biology and Ecology 208:1-12.

Ostfeld, R. S., and C. D. Canham. 1993. Effects of meadow vole population density on tree seedling survival in old fields. Ecology 74:1792-1801.

Ostfeld, R. S., R. H. Manson, and C. D. Canham. 1997. Effects of rodents on survival of tree seeds and seedlings invading old fields. Ecology 78:1531-1542.

Paramor, O. A. L., and R. G. Hughes. 2004. The effects of bioturbation and herbivory by the polychaete Nereis diversicolor on loss of saltmarsh in south-east England. Journal of Applied Ecology 41:449-463.

Paramor, O. A. L., and R. G. Hughes. 2007. Restriction of Spartina anglica (C.E. Hubbard) marsh development by the infaunal polychaete Nereis diversicolor (O.F. Muller). Estuarine Coastal and Shelf Science 71:202-209.

Regnier, E., S. K. Harrison, J. Liu, J. T. Schmoll, C. A. Edwards, N. Arancon, and C. Holloman. 2008. Impact of an exotic earthworm on seed dispersal of an indigenous US weed. Journal of Applied Ecology 45:1621-1629.

Rönn, C., E. Bonsdorff, and W. G. Nelson. 1988. Predation as a mechanism of interference within infauna in shallow brackish water soft bottoms; experiments with an infauna predator, Nereis diversicolor O.F. Müller. Journal of Experimental
Marine Biology and Ecology 116:143-157.

Scaps, P. 2002. A review of the biology, ecology and potential use of the common ragworm Hediste diversicolor (O.F. Müller) (Annelida: Polychaeta). Hydrobiologia 470: 203-218.

Shumway, D. L., and R. T. Koide. 1994. Seed preferences of Lumbricus terrestris L. Applied Soil Ecology 1:11-15.

Silliman, B. R., and S. Y. Newell. 2003. Fungal farming in a snail. Proceedings of the National Academy of Sciences of the United States of America 100:15643-15648.

Silva, P. D., I. R. Leal, R. Wirth, and M. Tabarelli. 2007. Harvesting of Protium heptaphyllum (Aubl.) March. seeds (Burseraceae) by the leaf-cutting ant Atta sexdens L. promotes seed aggregation and seedling mortality. Brazilian Journal of Botany 30:553-560.

Smith, D., R. G. Hughes, and E. J. Cox. 1996. Predation of epipelic diatoms by the amphipod Corophium volutator and the polychaete Nereis diversicolor. Marine Ecology Progress Series 145:53-61.

Vander Wall, S. B. 2010. How plants manipulate the scatterhoarding behaviour of seed-dispersing animals. Philosophical Transactions of the Royal Society B: Biological Sciences 365:989-997.

Wolters, M., and J. P. Bakker. 2002. Soil seed bank and driftline composition along a successional gradient on a temperate salt marsh. Applied Vegetation Science 5:55-62.

Zhu, Z., T. J. Bouma, T. Ysebaert, L. Zhang, and P. M. J. Herman. 2014. Seed arrival and persistence at the tidal mudflat: identifying key processes for pioneer seedling establishment in salt marshes. Marine Ecology Progress Series 513:97-109.

Zhu, Z., F. Cozzoli, N. Chu, M. Salvador, T. Ysebaert, L. Zhang, P. M. Herman, and T. J. Bouma. 2016. Interactive effects between physical forces and ecosystem engineers on seed burial: a case study using Spartina anglica. Oikos 125:98-106.

\section{SUPPORTING INFORMATION}

Additional supporting information may be found in the online version of this article at http://onlinelibrary.wiley.com/ doi/10.1002/ecy.1613/suppinfo 